\title{
Inhibition of Microbial Quorum Sensing Mediated Virulence Factors by Pestalotiopsis sydowiana
}

\author{
Paramanantham Parasuraman', B Devadatha ${ }^{2}$, V. Venkateswara Sarma ${ }^{2}$, \\ Sampathkumar Ranganathan ${ }^{3}$, Dinakara Rao Ampasala ${ }^{3}$, Dhanasekhar Reddy ${ }^{5}$, \\ Ranjith Kumavath ${ }^{5}$, In-Won Kim ${ }^{4}$, Sanjay K. S. Patel ${ }^{4}$, Vipin Chandra Kalia ${ }^{4 *}$, Jung-Kul Lee ${ }^{4 *}$, and \\ Busi Siddhardha ${ }^{1 *}$ \\ ${ }^{1}$ Department of Microbiology, School of Life Sciences, Pondicherry University, Puducherry 605014, India \\ ${ }^{2}$ Department of Biotechnology, School of Life Sciences, Pondicherry University, Puducherry 605014, India \\ ${ }^{3}$ Centre for Bioinformatics, School of Life Sciences, Pondicherry University, Puducherry 605014, India \\ ${ }^{4}$ Department of Chemical Engineering, Konkuk University, Seoul 05029, Republic of Korea \\ ${ }^{5}$ Department of Genomic Science, School of Biological Sciences, Central University of Kerala, Tejaswini Hills, Periya \\ (P.O), Kasaragod, Kerala 671320, India
}

Quorum sensing (QS)-mediated infections cause severe diseases in human beings. The control of infectious diseases by inhibiting QS using antipathogenic drugs is a promising approach as antibiotics are proving inefficient in treating these diseases. Marine fungal (Pestalotiopsis sydowiana PPR) extract was found to possess effective antipathogenic characteristics. The minimum inhibitory concentration (MIC) of the fungal extract against test pathogen Pseudomonas aeruginosa PAO1 was $1,000 \mu \mathrm{g} / \mathrm{ml}$. Sub-MIC concentrations $(250$ and $500 \mu \mathrm{g} / \mathrm{ml})$ of fungal extract reduced QSregulated virulence phenotypes such as the production of pyocyanin, chitinase, protease, elastase, and staphylolytic activity in P. aeruginosa PAO1 by $84.15 \%, 73.15 \%, 67.37 \%, 62.37 \%$, and $33.65 \%$, respectively. Moreover, it also reduced the production of exopolysaccharides $(74.99 \%)$, rhamnolipids $(68.01 \%)$, and alginate $(54.98 \%)$, and inhibited the biofilm formation of the bacteria by $90.54 \%$. In silico analysis revealed that the metabolite of $P$. sydowiana PPR binds to the bacterial QS receptor proteins (LasR and RhIR) similar to their respective natural signaling molecules. Cyclo(Leu-Pro) (CLP) and 4-Hydroxyphenylacetamide (4-HPA) were identified as potent bioactive compounds among the metabolites of $P$. sydowiana PPR using in silico approaches. The MIC values of CLP and 4-HPA against $P$. aeruginosa PAO1 were determined as 250 and $125 \mu \mathrm{g} / \mathrm{ml}$, respectively. All the antivirulence assays were conducted at sub-MIC concentrations of CLP $(125 \mu \mathrm{g} / \mathrm{ml})$ and 4-HPA $(62.5 \mu \mathrm{g} / \mathrm{ml})$, which resulted in marked reduction in all the investigated virulence factors. This was further supported by gene expression studies. The findings suggest that the metabolites of P. sydowiana PPR can be employed as promising QS inhibitors that target pathogenic bacteria.

Keywords: Pestalotiopsis sydowiana, Pseudomonas aeruginosa, anti-biofilm, anti-quorum sensing, gene expression, in silico

\section{Introduction}

Quorum sensing (QS) regulates the infectious diseases in bacteria [1]. It operates through the signaling molecules, that is, autoinducers. The QS system in bacteria coordinates and influences the expression of genes responsible for the secretion of various virulence factors and biofilm formation, which lead to pathogenicity. Inhibition of QSmediated gene expression can help control bacterial infection and biofilm development without affecting their growth pattern $[2,3]$. Due to this unique feature, the bacteria develop less resistance to QSIs compared to antibiotics [4]. In recent years, various QS inhibitors of chemical and biological origin have been reported [5-8].

Pseudomonas aeruginosa is an opportunistic human pathogen that causes several clinical complications including chronic lung infection in cystic fibrosis patients $[9,10]$. P. aeruginosa infection operates via the QSmediated expression of several virulence traits like elastase, lipopolysaccharide, rhamnolipids, pyocyanin, cyanide, and exotoxin as well as flagellar motility, biofilm maturation, antimicrobial resistance, and alginates, which lead to biofilm formation [11]. Rhamnolipids play a significant role in evading the host immune response and facilitate the bacteria in successfully establishing the infection [12]. The infection system of $P$. aeruginosa is 
coordinated by acyl-homoserine lactone (AHL) genes for the two QS systems, that is, LasIR and RhlIR. Both of these systems get activated in a cascade manner by their specific signaling molecules, 3 -oxo- $\mathrm{C}_{12}-\mathrm{HSL}$ and $\mathrm{C}_{4}$-HSL, respectively $[9,13]$. Drugs are being developed to effectively target the QS mechanism in order to control the P. aeruginosa infection [14].

Bioactive compounds from diverse organisms are gaining immense attention as QSIs [1, 15-24]. The present study aims to discover novel QSIs from the marine fungus against the biofilm-forming ability of $P$. aeruginosa $\mathrm{PAO} 1$, an opportunistic pathogen.

\section{Materials and Methods}

\section{Microbial Strains, Culture Media, and Conditions}

Fungi from dry wood samples were isolated on an agar plate and grown in $2 \%$ malt extract medium at $28 \pm 2^{\circ} \mathrm{C}$ for 21 days. For the extraction of crude metabolites, the fungal isolates were cultivated in malt extract broth at same incubation conditions as aforementioned. P. aeruginosa PAO1, gifted by Dr. E. Peter Greenberg (Department of Microbiology, University of Washington and School of Medicine, USA), was cultured on Luria-Bertani (LB) agar plate or broth at $37^{\circ} \mathrm{C}$. Chromobacterium violaceum, biosensor strain was cultured at $37^{\circ} \mathrm{C}$ in $\mathrm{LB}$ medium. For bioassay on plate to evaluate the effect of fungal crude extract on the production of violacein, an active culture of C. violaceum was inoculated in LB soft agar $(0.8 \%$ agar $)$ at $1.5 \times 10^{8} \mathrm{CFU} / \mathrm{ml}$ cell density and this mixture was plated on the surface of LB agar plate.

\section{Collection of Samples, Isolation of Fungi, and Preparation of Crude Extract}

Different dry wood samples were collected from the coast near the village of Muthupet, Cuddalore District, Tamil $\mathrm{Nadu}$, India. Isolation of fungal species was executed by applying single spore isolation technique on malt extract agar. Morphologically distinct colonies of fungi were isolated and stored at $-80^{\circ} \mathrm{C}$ with $25 \%$ glycerol. The selected fungal isolates were cultured for crude extract. Briefly, the fungi were subcultured in malt extract broth for 24 days and incubated at static conditions at $28 \pm 2^{\circ} \mathrm{C}$ by adding $2 \%$ of inoculum in the culture medium. The cell-free supernatant of the culture broth was collected after centrifugation at $10,000 \times g$ for $15 \mathrm{~min}$. To this, ethyl acetate $(1: 1 \mathrm{v} / \mathrm{v})$ was mixed and stirred well for $1 \mathrm{~h}$. The organic phase was isolated and dried using the rotary evaporator [25]. The dried crude extracts of the fungi were diluted in 10\% sterile DMSO to prepare the stock solution of $2 \mathrm{mg} /$ $\mathrm{ml}$ and were used in the screening assays against the indicator strain. The process of fungal crude extraction was performed in three independent experiments and studied for anti-QS activity. All the fungal isolation and crude extraction procedures in this study were performed in the Fungal Toxicology Lab, Department of Biotechnology, Pondicherry University.

\section{Screening of Fungal Isolates for Their Violacein Inhibition Activity}

Inhibition of violacein production in C. violaceum by fungal isolates was determined using the double layer agar diffusion method. Briefly, on a solid LB agar plate, the molten LB soft agar was seeded with $1.5 \times 10^{8} \mathrm{CFU} / \mathrm{ml}$ of indicator strain and allowed to solidify. Wells were prepared using $8 \mathrm{~mm}$ metal borer and filled with two different concentrations of fungal crude extract and incubated at $37^{\circ} \mathrm{C}$ for $24 \mathrm{~h}$. Inhibition of violacein production was represented as zone of inhibition in $\mathrm{mm}$ [26].

\section{Identification of Fungal Isolates}

The fungal isolate presenting good anti-QS activity was identified by amplifying ITS region using ITS1 (5' TCCGTAGGTGAACCTGCGG $3^{\prime}$ ) as forward primer and ITS4 (5' TCCTCCGCTTATTGATATGC $3^{\prime}$ ) as reverse primer (Macrogen Inc., Seoul, South Korea). The nucleotide sequence result was equated with the DNA sequence in NCBI GenBank (https://blast.ncbi.nlm.nih.gov/Blast.cgi) to determine the closely related species. The ITS gene sequence of fungal isolate (PPR) was deposited to the NCBI GenBank database. Phylogeny was inferred using the neighbor-joining method in MEGA 5.04 software after aligning the sequences with CLUSTAL_W, and bootstrap analysis was carried out with 1000 replications [27].

Determination of Minimum Inhibitory Concentration (MIC) and Growth Curve Analysis

MIC of the fungal crude extract was determined using the microdilution method in order to study the effect of subinhibitory concentration (Sub-MIC) on QS-regulated virulence factors of the test bacterium, $P$. aeruginosa [28]. About $2 \mathrm{mg} / \mathrm{ml}$ of fungal crude extract was used as the initial concentration and was diluted 2-fold in LB broth to a total volume of $200 \mu \mathrm{l}$ in the microtiter plates. The wells were inoculated with $2 \mu \mathrm{l}$ of bacterial suspension $\left(1.5 \times 10^{8}\right)$. The assay was performed in triplicate and the sample was incubated at $37^{\circ} \mathrm{C}$ for $24 \mathrm{~h}$. After incubation, the absorbance of each well was recorded at $600 \mathrm{~nm}$.

Growth curve analysis was performed to determine the effect of sub-MIC of fungal crude extract on the growth of the test pathogen, P. aeruginosa PAO1 [29]. Overnight bacterial suspension was inoculated into $0.1 \mathrm{~L}$ of LB broth in $0.25 \mathrm{~L}$ conical flask, and the fungal extracts $(250$ and $500 \mu \mathrm{g} / \mathrm{ml})$ were added. The flasks were incubated at $37^{\circ} \mathrm{C}$ on a rotary incubator at $120 \mathrm{rpm}$ and the absorbance of broth was monitored at $600 \mathrm{~nm}$ for every $1 \mathrm{~h}$ up to $24 \mathrm{~h}$.

\section{Violacein Inhibition Assay}

The potential of the fungal extract in suppressing the violacein synthesis in C. violaceum was quantified by employing the procedure followed by Ma et al. [30]. The overnight grown C. violaceum was altered to an optical density of 0.5 at $600 \mathrm{~nm}$. Aliquots of $100 \mu \mathrm{l}$ were inoculated in the test tube containing $2 \mathrm{ml}$ of LB and incubated with or without adding the sub-MIC concentrations $(250$ and $500 \mu \mathrm{g} / \mathrm{ml})$ of fungal extract. The tubes were 
incubated at $37^{\circ} \mathrm{C}$ for $18 \mathrm{~h}$. The culture suspensions were centrifuged at $10,000 \times g$ for $15 \mathrm{~min}$ and the bacterial pellet was collected. Next, $1 \mathrm{ml}$ of DMSO was added to every tube and vigorously shaken for $1 \mathrm{~h}$. The bacterial culture treated with $10 \%$ DMSO serving as a negative control. The suspensions were centrifuged at $12,000 \times g$ for $10 \mathrm{~min}$, the supernatants were collected, and the optical density of the supernatant was determined at $590 \mathrm{~nm}$.

\section{Pyocyanin Production}

Quantitative determination of the effect of fungal extract on pyocyanin synthesis in P. aeruginosa was investigated, as described previously, with minor modifications [31]. The supernatant of overnight grown P. aeruginosa PAO1, in the presence or absence of fungal extract, was collected and used to extract the pyocyanin pigment from the culture supernatant. The optical density of the resultant pink-colored solution was recorded at $520 \mathrm{~nm}$.

\section{Azocasein-Degrading Proteolytic Activity}

The effect of fungal extract on protease synthesis in P. aeruginosa was determined by azocasein assay. The cell-free supernatant of the overnight cultured $P$. aeruginosa $\mathrm{PAO} 1$ in presence or absence of fungal extract was imparted to azocasein $(0.5 \%$ in $100 \mathrm{mM}$ Tris buffer with $\mathrm{pH} 8)$, followed by incubation at $28^{\circ} \mathrm{C}$ for $1 \mathrm{~h}$. After the incubation, $10 \%$ trichloroacetic acid was added to the reaction mixture and incubated at $4^{\circ} \mathrm{C}$ for $20 \mathrm{~min}$. The mixture was then centrifuged at 12,000 $\times \mathrm{g}$ for $10 \mathrm{~min}$ and supernatant was collected. Equal volumes of $1 \mathrm{M} \mathrm{NaOH}$ solution were added to the supernatant and the absorbance was measured at $420 \mathrm{~nm}$ [26].

\section{Elastase and Chitinase Assay}

Elastolytic activity was determined by Elastin-Congo red (ECR) method [32]. Supernatant $(0.1 \mathrm{ml})$ obtained from the overnight grown P. aeruginosa, with or without treatment of fungal extract, was added to $0.9 \mathrm{ml}$ of ECR buffer $\left(0.1 \mathrm{M}\right.$ Tris, $0.01 \mathrm{M} \mathrm{CaCl}_{2}, \mathrm{pH} \mathrm{7.5)}$ and incubated at $37^{\circ} \mathrm{C}$ for $4 \mathrm{~h}$ on a rotary shaker. The reaction was hindered by adding $100 \mu \mathrm{l}$ of $0.12 \mathrm{M}$ EDTA at $4^{\circ} \mathrm{C}$. The reaction mixture was centrifuged $(10,000 \times g$ for $15 \mathrm{~min})$ to remove the insoluble ECR, and the absorbance of the supernatant was recorded at $495 \mathrm{~nm}$.

Chitinase assay was performed by adopting the method described previously with slight modifications [33]. The culture supernatant obtained from the overnight grown $P$. aeruginosa PAO1, with or without treatment with sub-MIC concentrations of fungal extract, was added in 2:1 with $100 \mathrm{mM}$ sodium citrate buffer ( $\mathrm{pH} 4.8$ ), also containing chitin azure $(0.05 \%)$. The reaction mixture was incubated on a rotary shaker at $37^{\circ} \mathrm{C}$ for a week. After the incubation period, the absorbance of the reaction mixture was recorded spectrophotometrically at $570 \mathrm{~nm}$.

\section{Staphylolytic Activity}

Staphylolytic assay was performed to determine the effect of fungal extract on the LasA protease behavior of supernatant obtained for P. aeruginosa PAO1 on boiled Staphylococcus aureus cells [34]. The cell-free supernatant $(100 \mu \mathrm{l})$ was added to $0.9 \mathrm{ml}$ of the overnight cultured P. aeruginosa PAO1 in presence or absence of the fungal extract of boiled $S$. aureus suspension. Supernatant of the P. aeruginosa PAO1, cultured with 10\% DMSO, was considered as a negative control. The change in the optical density was measured at 0 - and 60-min. Activity was expressed as the percentage inhibition compared to control.

\section{Swimming and Swarming Motility Assay}

Swimming and swarming motility was determined as described elsewhere [35]. Briefly, on the medium (1\% tryptone, $0.5 \% \mathrm{NaCl}$, and $0.3 \%$ agar) for swimming and for swarming ( $1 \%$ peptone, $0.5 \% \mathrm{NaCl}, 0.5 \% \mathrm{D}$-fructose, and $0.6 \%$ agar) amended with or without the fungal extract, was point inoculated with the test bacterium and incubated at $37^{\circ} \mathrm{C}$ for $24 \mathrm{~h}$. After the incubation period, the plates were compared with the control (treated with $10 \%$ DMSO).

\section{Effect of Fungal Extract Against the Biofilm of P. aeruginosa PAO1}

The effect of fungal extract on biofilm development in P. aeruginosa was evaluated by a method described by Yin $e t$ al. [36]. The test bacterium was cultured in LB broth supplemented with $1 \%$ glucose in presence or absence of fungal extract, in a microtiter plate at $37^{\circ} \mathrm{C}$ for $24 \mathrm{~h}$. After incubation, the culture suspension was separated and washed gently to remove the planktonic cells in the wells. The biofilm was stained with $0.1 \%$ crystal violet solution and the excess stain was removed using repeated washings. The dye adsorbed to the biofilm was solubilized using ethanol and measured spectrophotometrically at $570 \mathrm{~nm}$.

\section{Exopolysaccharide (EPS) Production}

EPS production by the test bacterium was qualitatively determined using Congo red agar (CRA) plate method [37]. The test bacterium, P. aeruginosa, was cultured on the CRA medium (3.7\% brain-heart infusion broth, 3.6\% sucrose, $1.5 \%$ agar, and $0.08 \%$ Congo red), with or without fungal extract, and was incubated at $37^{\circ} \mathrm{C}$ for $24 \mathrm{~h}$. Supernatant obtained from the culture broth was mixed with chilled absolute ethanol and left overnight at $4^{\circ} \mathrm{C}$ to precipitate EPS. The amount of the EPS was estimated by employing the method of Husain et al. [33], and the result was represented as percentage inhibition.

\section{Rhamnolipid Quantification}

The effect of fungal extract on rhamnolipid production by P. aeruginosa was evaluated using the Orcinol method, as explained by Luo et al. [38]. One-milliliter supernatant of $P$. aeruginosa PAO1, cultured with or without fungal extract, was altered to $\mathrm{pH} 2.0$, with $\mathrm{HCl}$. An equal volume of ethyl acetate was added to the supernatant to 
solubilize the metabolites and the organic phase was separated and completely dried. The dried compounds were dissolved in $0.1 \mathrm{ml}$ of milliQ water and $0.9 \mathrm{ml}$ of orcinol solution $[0.19 \%$ orcinol solution was prepared in $53 \%(\mathrm{v} / \mathrm{v})$ $\mathrm{H}_{2} \mathrm{SO}_{4}$. The mixture was incubated at $80^{\circ} \mathrm{C}$ for $30 \mathrm{~min}$ and the optical density was measured at $421 \mathrm{~nm}$.

\begin{abstract}
Alginate Production
The effect of fungal extract on synthesis of alginate by $P$. aeruginosa PAO1 was investigated using the method described by Gopu et al. [39]. Briefly, the $70 \mu$ of overnight cultured P. aeruginosa PAO1, in the presence or absence of the fungal extract, was mixed with $600 \mu \mathrm{l}$ of boric acid-sulphuric acid mixture at a ratio of 4:1 under cold conditions. The mixture was vortexed and $20 \mu \mathrm{l}$ of $0.2 \%$ carbazole dissolved in ethanol was added. The reaction mixture was vortexed for $10 \mathrm{sec}$ and incubated at $55^{\circ} \mathrm{C}$ for $30 \mathrm{~min}$. The optical density of the reaction mixture after incubation was measured at $530 \mathrm{~nm}$.
\end{abstract}

\title{
Microscopic Analysis
}

The effect of fungal extract on the biofilm development in P. aeruginosa PAO1 was determined via microscopic analysis as described previously by Kalia et al. [29]. The test bacterium was cultured on a cover slip, in presence or absence of fungal extract, and was washed with phosphate-buffered saline (PBS) to remove the unadhered cells. For light microscopic observation, the cover slips were stained with $0.4 \%$ crystal violet solution; whereas, for confocal laser scanning microscopy (CLSM), the biofilm-coated cover slips were stained with $0.01 \%$ acridine orange solution and incubated for $10 \mathrm{~min}$. After incubation, the excess stain was removed by washing several times with sterile PBS and visualized under a light microscope (100× magnification) and CLSM (40× magnification).

\section{Gas Chromatography-Mass Spectrometry (GC-MS) Analysis}

The metabolites present in the crude extract were determined using GC-MS analysis. The GC model Clarus 680 with an ion-trap mass spectrometer model Clarus 600 (EI), equipped with Elite-5MS column having specifications of $30 \mathrm{~m}$ in length and $0.25 \mathrm{~mm}$ in thickness of the film, was employed for this experiment. The compounds were detected using an electron ionization system, which uses higher energy electrons $(70 \mathrm{eV})$. Helium gas was applied as a carrier gas with a constant run of $1 \mathrm{ml} / \mathrm{min}$. The temperature at the initial stage was set as $260^{\circ} \mathrm{C}$ and programmed with an increasing rate of $10^{\circ} \mathrm{C}$ per min during the chromatographic run. Next, $1 \mu \mathrm{l}$ of fungal extract diluted in ethyl acetate was injected. By using GC-MS NIST (2008), the bioactive compounds present in the fungal extract were identified [40].

\section{Receptor Protein Retrieval, Modeling, and Validation}

The ligand binding domain of LasR was retrieved from the Protein Data Bank (PDB) ID:2UV0. The threedimensional (3D) structure of the RhlR receptor molecule was built from the protein sequence retrieved from UniPort database (ID: P54292.1) in the ROBETTA server for protein structure modeling. The overall stereo chemistry quality assessment of the generated model of the RhlR structure was validated in the RAMPAGE web server (http://mordred.bioc.cam.ac.uk/ rapper/rampage.php) [41]. The best RhlR 3D-model after validation was selected for the docking studies.

\section{Molecular Docking}

The docking studies were carried out in Schrodinger Maestro software version 11.5 (Schrodinger, LLC, New York, NY, 2018) in order to understand the interaction of fungal metabolites against two major QS receptor proteins, LasR and RhlR, using the natural ligands, 3 -oxo- $\mathrm{C}_{12}-\mathrm{HSL}$ and $\mathrm{C}_{4}-\mathrm{HSL}$ as reference molecules, respectively. The LasR and RhlR ligand binding domain molecule protein preparation was carried out using the protein preparation wizard of Maestro suite with default settings. The grid files were generated individually using Glide, version 7.8, in the Maestro software. For LasR, the docking site was generated around its autoinducer (3-oxo- $\mathrm{C}_{12}$-HSL) interacting residues, and the grid for RhlR was defined vicinity of the active site residue Trp-68 of its natural autoinducer $\left(\mathrm{C}_{4}-\mathrm{HSL}\right)$ [42]. The known anti-QS molecules biacelein and furanone $\mathrm{C} 30$ were used as positive controls for the QS receptors LasR and RhlR, respectively. The 3D structure files of all fungal metabolites from GC-MS analysis were collected from the PubChem database and prepared in the LigPrep module of Maestro software version 11.5 with enabled Epik option where other settings were set as default. The prepared receptor grids and ligands were docked in Glide, version 7.8 in Maestro suite, with enabled Extra Precision mode [43]. LigPlot+ version 1.4.5 and Chimera version 1.6.2 were used for $2 \mathrm{D}$ and $3 \mathrm{D}$ analysis, respectively. Among the identified compounds, two compounds, cyclo(-Leu-Pro) (CLP) and 4-hydroxyphenyl acetamide (4-HPA), showed promising docking scores with the QS receptors similar to those of the natural ligands. Thus, these compounds were subjected to the molecular dynamics simulation analysis to investigate the conformational changes in the QS receptor proteins following interaction with the natural ligands or bioactive compounds.

\section{Molecular Dynamics Simulation}

The results of molecular docking did not reveal the conformational changes found globally among the receptor proteins after interaction with their respective natural ligands or bioactive compounds, since the docking scores of interaction between the receptor and the ligand were determined at a particular region at a specific time. Through the molecular dynamics simulation study, we were able to detect the unwanted modification in the topology of the protein. The complexes of QS receptor proteins with selected bioactive compounds were simulated using GROMOS force field in the GROMACS v5.1.2 software [44]. The system was equilibrated under NVT and NPT ensembles before a final MD run of 50,000 ps with a time step of $2 \mathrm{fs}$. Post-simulation binding free energy of the 
complex formed by QS receptor protein and its natural ligand or bioactive compound and the interaction energy values were estimated using the Molecular Mechanics Poisson-Boltzmann Surface Area (MM/PBSA) analysis [45].

Effect of Bioactive Compounds of P. sydowiana PPR Crude Extract on P. aeruginosa PAO1

Based on the in silico results, the bioactive compounds CLP and 4-HPA were observed to show promising anti-QS properties, which were further confirmed by evaluating the bioactive compounds for their anti-QS activity against P. aeruginosa PAO1 [46]. The commercially available CLP (Spec-Chem, China) was dissolved in methanol (2 mg/ $\mathrm{ml}$ ), whereas 4-HPA (Alfa Aesar, India) was dissolved in sterile distilled water $(2 \mathrm{mg} / \mathrm{ml}$ ). Baicalein (SigmaAldrich, India), used as a positive control in this study, was dissolved in methanol $(2 \mathrm{mg} / \mathrm{ml})$. Varying concentrations of these commercially available bioactive compounds were prepared $(800,400,200,100,50,25$, and $12.5 \mu \mathrm{g} / \mathrm{ml}$ ) in respective test tubes containing $1 \mathrm{ml}$ of Mueller Hinton broth and $1 \%$ of P. aeruginosa PAO1 followed by incubation at $37^{\circ} \mathrm{C}$ for $18 \mathrm{~h}$. The cell density of $P$. aeruginosa PAO1 treated with or without the bioactive compounds was measured at $600 \mathrm{~nm}$ using UV-Visible spectrophotometer, and MIC was calculated.

The sub-MIC values of CLP and 4-HPA (100 and $62.5 \mu \mathrm{g} / \mathrm{ml})$ were tested for anti-QS potential by assessing pyocyanin, chitinase, elastase, and staphylolytic activities as well as motility inhibition and reduction in biofilm formation according to the protocols mentioned above.

\section{Gene Expression Studies}

The effect of fungal bioactive compounds on the virulence genes of P. aeruginosa PAO1 was tested using RT-PCR. The test pathogen was grown in the LB broth with or without bioactive compounds at $37^{\circ} \mathrm{C}$ for $24 \mathrm{~h}$. After incubation, the bacterial cell pellets were harvested by centrifugation at $10,000 \times g$ for $5 \mathrm{~min}$. The cell pellets were resuspended in TRIzol reagent (Sigma-Aldrich, India) and total RNA was isolated according to the manufacturer's guidelines. The purity and concentration of the RNA were measured using Nanodrop (Thermo Fisher Scientific, USA) and the isolated RNA was preserved at $-80^{\circ} \mathrm{C}$. The RNA was converted into cDNA using a RevertAid First Strand cDNA synthesis kit (Thermo Scientific, USA) according to the manufacturer's instructions.

RT-PCR was performed in a total volume of $10 \mu \mathrm{l}$ containing SYBR Green Master Mix (Thermo Scientific, USA) on a Roche Light Cycle 480 system using appropriate primers (Table S1). The PCR cycling conditions were as follows: initial denaturation at $95^{\circ} \mathrm{C}$ for 10 min followed by denaturation at $95^{\circ} \mathrm{C}$ for $30 \mathrm{sec}$, annealing for $15 \mathrm{sec}$ as mentioned in Table $\mathrm{S} 1$ and extension at $72^{\circ} \mathrm{C}$ for $15 \mathrm{~min}$. These conditions were maintained for $45 \mathrm{cycles}$ and the final extension was performed at $72^{\circ} \mathrm{C}$ for $5 \mathrm{~min}$ [46]. All samples were analyzed in triplicates and normalized to proC gene expression.

\section{Statistical Analysis}

All the experiments were conducted thrice, and the data of the assays were expressed as mean values with standard deviation.

\section{Results}

\section{Isolation and Screening of the Anti-QS Potential of Fungi}

Fungi with anti-QS potential were isolated from the dry wood samples collected from the marine environment. A total of 14 distinct colonies of fungi were obtained as pure cultures using the single-spore isolation technique. The crude extracts from 14 fungal isolates showed variable degree of inhibition on violacein and pyocyanin production by C. violaceum and P. aeruginosa, respectively (Table 1). The halo inhibition zones around the wells were observed. Among the 14 fungal isolates, PPR revealed promising violacein inhibition activity without

Table 1. Preliminary screening of extract of different fungal isolates against QS systems in the biosensor strain and test pathogen.

\begin{tabular}{|c|c|c|c|c|}
\hline \multirow{3}{*}{ Sample Code } & \multicolumn{4}{|c|}{ Zone of inhibition (mm) } \\
\hline & \multicolumn{2}{|c|}{ Chromobacterium violaceum } & \multicolumn{2}{|c|}{ Pseudomonas aeruginosa $\mathrm{PAO} 1$} \\
\hline & $250 \mu \mathrm{g} / \mathrm{ml}$ & $500 \mu \mathrm{g} / \mathrm{ml}$ & $250 \mu \mathrm{g} / \mathrm{ml}$ & $500 \mu \mathrm{g} / \mathrm{ml}$ \\
\hline PPR & $19.33 \pm 1.52$ & $24.67 \pm 1.15$ & $14.33 \pm 2.08$ & $19.00 \pm 1.00$ \\
\hline $\mathrm{MC1}$ & $16.30 \pm 1.53$ & $16.30 \pm 1.53$ & $11.70 \pm 1.53$ & $14.00 \pm 2.00$ \\
\hline PM6 & $12.33 \pm 0.57$ & $14.00 \pm 2.64$ & $11.67 \pm 1.52$ & $15.33 \pm 1.15$ \\
\hline De20 & $11.67 \pm 0.57$ & $12.67 \pm 1.52$ & $9.00 \pm 0.57$ & $12.67 \pm 0.57$ \\
\hline DM19 & $11.00 \pm 1.00$ & $14.67 \pm 1.52$ & $8.33 \pm 0.57$ & $12.00 \pm 1.00$ \\
\hline DM15 & $10.67 \pm 0.57$ & $9.33 \pm 1.52$ & $9.66 \pm 1.52$ & $10.33 \pm 0.57$ \\
\hline DM2 & $11.00 \pm 1.00$ & $12.33 \pm 2.08$ & $8.00 \pm 0.00$ & $10.33 \pm 1.52$ \\
\hline DM38 & $11.00 \pm 1.00$ & $9.33 \pm 1.52$ & $8.00 \pm 0.00$ & $8.66 \pm 1.15$ \\
\hline DE29 & $9.66 \pm 1.52$ & $13.33 \pm 1.15$ & $10.00 \pm 1.00$ & $12.00 \pm 2.00$ \\
\hline DM32a & $9.00 \pm 1.00$ & $10.33 \pm 1.15$ & $8.33 \pm 0.57$ & $8.33 \pm 0.57$ \\
\hline DM25 & $8.66 \pm 0.57$ & $13.00 \pm 1.00$ & $9.00 \pm 1.00$ & $11.00 \pm 1.00$ \\
\hline DE27 & $8.33 \pm 0.57$ & $13.33 \pm 1.15$ & $8.66 \pm 1.15$ & $9.33 \pm 1.15$ \\
\hline DE09 & $8.33 \pm 0.57$ & $11.33 \pm 1.52$ & $8.00 \pm 0.00$ & $12.00 \pm 0.00$ \\
\hline DM33 & $8.33 \pm 0.57$ & $11.67 \pm 1.52$ & $8.00 \pm 0.00$ & $9.00 \pm 1.00$ \\
\hline
\end{tabular}




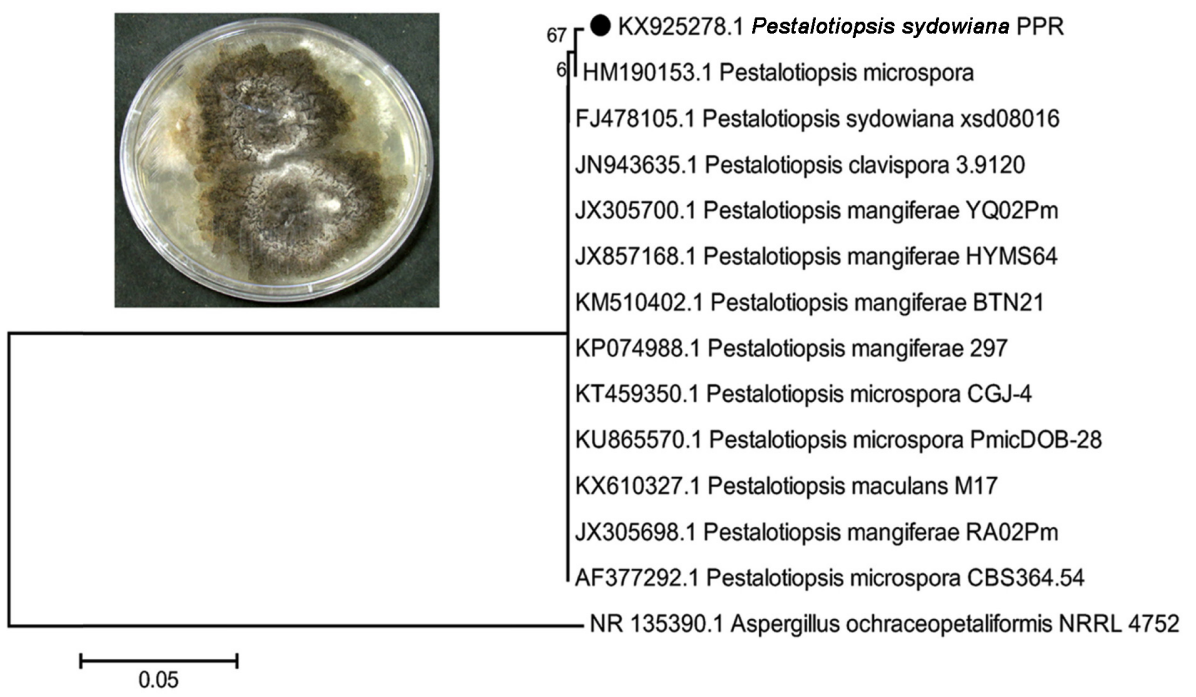

Fig. 1. Culture plate image of Pestalotiopsis sydowiana PPR and phylogenetic tree based on ITS rRNA sequences using neighbor-joining of the strain P. sydowiana PPR. Branch distances represent the nucleotide substitution rate and scale bar represents the changes per nucleotide position.

exhibiting bactericidal activity. The fungal isolate PPR was selected further for batch fermentation process, followed by crude extract preparation and determination of anti-QS activity.

\section{Characterization of Fungal Isolate}

The light and phase contrast microscopic observations of PPR isolate presented an appendage-bearing conidial anamorphic form. The partial ITS rRNA gene sequence revealed $99 \%$ similarity with Pestalotiopsis sydowiana. The resulted sequence was aligned with closely associated Pestalotiopsis sp. obtained from the NCBI GenBank database. The resulted phylogenetic tree revealed similarity with $P$. sydowiana with a resemblance matrix bootstrap value of 67 (Fig. 1). The GenBank accession number for the obtained partial ITS rRNA gene sequence of P. sydowiana strain is KX925278.

Effect of Crude Extract on P. aeruginosa PAO1 Growth

The MIC was calculated using concentrations of fungal extract from 3.90 to $4,000 \mu \mathrm{g} / \mathrm{ml}$. The fungal extract did not exhibit bactericidal effect on P. aeruginosa (Fig. 2A). The MIC of the fungal extract against $P$. aeruginosa PAO1 was $1,000 \mu \mathrm{g} / \mathrm{ml}$; hence, further experiments were performed at sub-MIC concentrations of 250 and $500 \mu \mathrm{g} / \mathrm{ml}$. The effect of sub-MIC concentrations of fungal extract on the growth curves of $P$. aeruginosa PAO1 (Fig. 2B) revealed that neither of the sub-MIC concentrations $(250$ and $500 \mu \mathrm{g} / \mathrm{ml})$ exhibited significant effect on the growth of the test pathogen; however, a reduction in the growth rate was detected at $500 \mu \mathrm{g} / \mathrm{mL}$ concentration, which could affect the bacterial QS.

\section{Effect of Fungal Extract on Violacein Production and Virulence Traits of P. aeruginosa PAO1}

Violacein synthesis in C. violaceum was determined in the presence or absence of crude extract of PPR isolate and found to reduce with the increase in the concentration of fungal extract. The test results revealed inhibition in the violacein production by $80.86 \pm 2.36 \%$ and $92.58 \pm 4.73 \%$ at concentrations of 250 and $500 \mu \mathrm{g} / \mathrm{ml}$ of fungal extract, respectively.

The ability of fungal extract in reducing the QS-dependent virulence phenotypes of P. aeruginosa PAO1 is illustrated in Fig. 2C. The activity of virulence phenotypes such as pyocyanin, protease, elastase, chitinase, and staphylolytic activity of $P$. aeruginosa $\mathrm{PAO} 1$ was downregulated by fungal extract in a dose-dependent manner. The results of pyocyanin production revealed $54.22 \pm 6.41 \%$ and $64.38 \pm 4.91 \%$ reduction in the test bacterium on treatment with fungal extract $(250$ and $500 \mu \mathrm{g} / \mathrm{ml})$, respectively. The activities of different lytic enzymes including protease $(68.05 \pm 5.93 \%)$, elastase $(62.61 \pm 4.23 \%)$, and chitinase $(69.86 \pm 5.91 \%)$ were also considerably reduced on treatment with a $500 \mu \mathrm{g} / \mathrm{ml}$ concentration fungal extract at sub-MIC concentrations (Fig. 2C). The staphylolytic activity was inhibited by $62.09 \pm 2.48 \%$ and $73.70 \pm 3.16 \%$ on treatment with 250 and $500 \mu \mathrm{g} / \mathrm{ml}$ concentrations of fungal extract, respectively.

\section{Inhibition of Motility and Microscopic Observation of Biofilms}

The effect of fungal extract in suppressing both swimming and swarming motility of P. aeruginosa PAO1 is illustrated in Fig. S1. The fungal extract at a concentration of $500 \mu \mathrm{g} / \mathrm{ml}$ exhibited comparatively higher inhibition rates of both swimming and swarming motility in P. aeruginosa PAO1. The observation of biofilm under light microscope and CLSM revealed the effect of fungal extract on biofilm, and the fungal extract $(500 \mu \mathrm{g} / \mathrm{ml})$-treated samples presented scattered cells with less intensity as compared to the developed biofilm in the control (Fig. 3). 

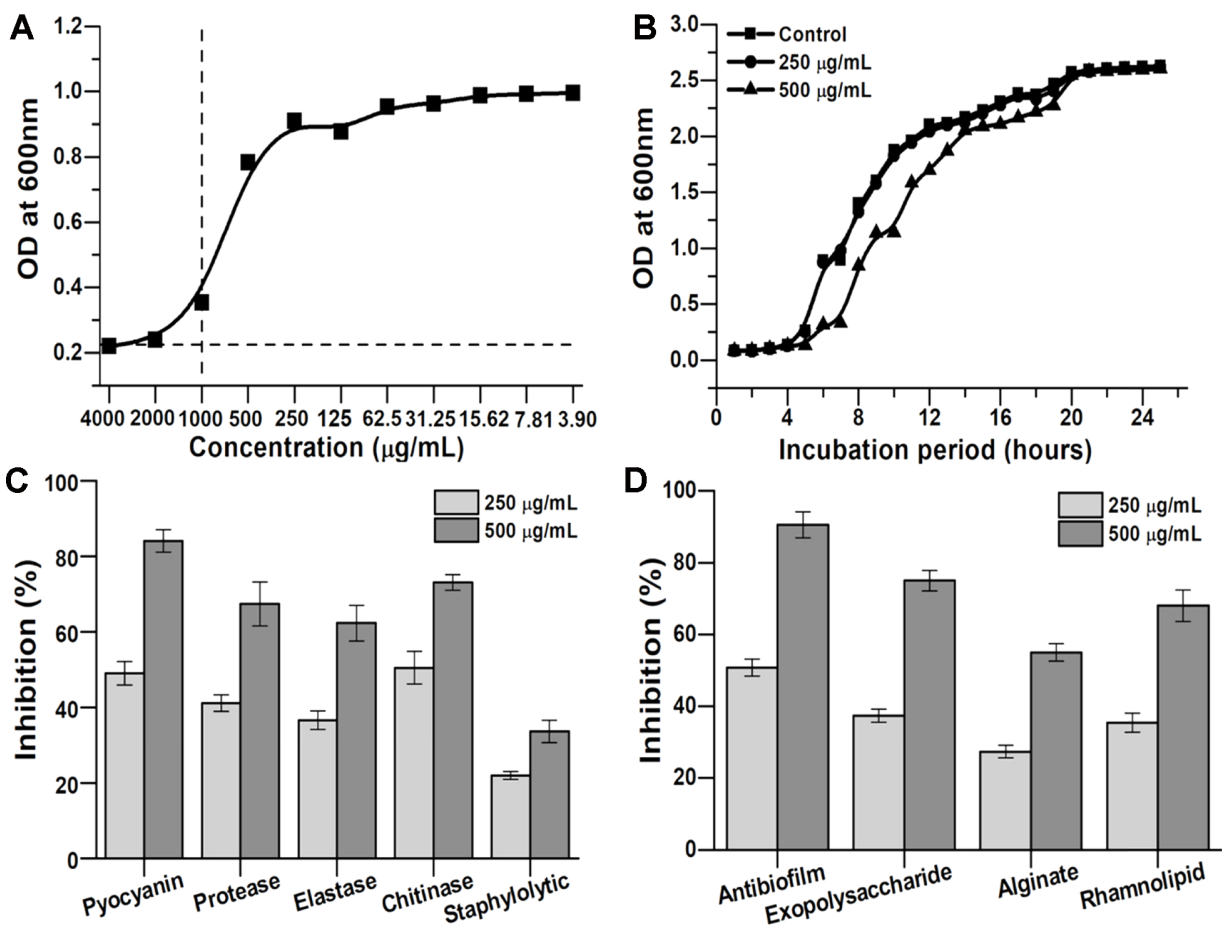

Fig. 2. (A) Minimum inhibitory concentration of Pestalotiopsis sydowiana PPR extract on Pseudomonas aeruginosa PAO1; (B) Growth curve analysis of P. aeruginosa PAO1 treated with 250 and $500 \mu \mathrm{g} / \mathrm{ml}$ concentrations of fungal crude extract; (C)Effect of crude extract on QS-regulated virulence factors of Pseudomonas aeruginosa PAO1; (D) Effect of sub-MIC concentration of crude extract on biofilm attributes of P. aeruginosa PAO1.

Effect of Fungal Extract on Biofilm of P. aeruginosa PAO1

The crude extract of PPR exhibited significant inhibition of $P$. aeruginosa PAO1 biofilm development (Fig. 2D). The percentage of antibiofilm activity was observed as $54.30 \pm 1.17 \%$ and $72.42 \pm 3.89 \%$ at 250 and $500 \mu \mathrm{g} / \mathrm{ml}$ concentrations of the fungal extract.

Inhibition of EPS, Rhamnolipid, and Alginate Production

The qualitative detection of the EPS production performed using Congo red plates is presented in Fig. S1. The control plate with black-colored colonies of $P$. aeruginos $\mathrm{PAO} 1$ on Congo red agar indicated the production of the EPS, whereas the Congo red plate mixed with sub-MIC concentration $(500 \mu \mathrm{g} / \mathrm{ml})$ of fungal extract revealed the

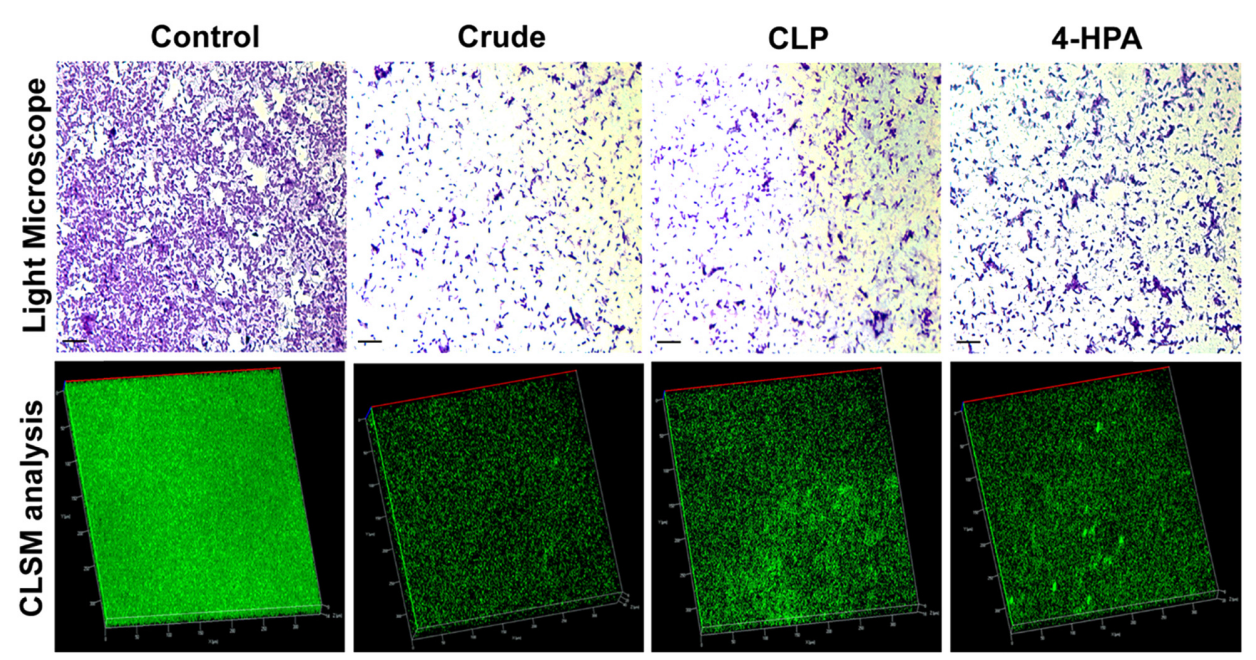

Fig. 3. Microscopic observation of antibiofilm activity of fungal extract Pestalotiopsis sydowiana PPR and its bioactive compounds at sub-MIC concentration against Pseudomonas aeruginosa PAO1. 
growth of test bacterium without black-colored colonies indicating the inhibition of EPS production. The production of EPS in P. aeruginosa PAO1 treated with $250 \mu \mathrm{g} / \mathrm{ml}$ concentration of fungal extract was $60.80 \pm$ $6.69 \%$; whereas, about $74.99 \pm 2.90 \%$ of EPS inhibition was observed at $500 \mu \mathrm{g} / \mathrm{ml}$ concentration of fungal extract (Fig. 2D). Rhamnolipid production in P. aeruginosa is an important virulence factor that plays a pivotal role in cell adhesion and biofilm formation. The synthesis of rhamnolipid ( $43.14 \pm 3.69 \%$ and $61.09 \pm 5.16 \%)$ by P. aeruginosa PAO1 was inhibited on treatment with 250 and $500 \mu \mathrm{g} / \mathrm{ml}$ concentrations of fungal crude extract, respectively. These results suggest the effect of fungal extract on rhamnolipid production of $P$. aeruginosa PAO1 in a dosedependent manner (Fig. 2D). Alginate is a major component of $P$. aeruginosa PAO1 during biofilm development. About $38.20 \pm 3.64 \%$ and $60.37 \pm 3.03 \%$ inhibition in production of alginate was observed at concentrations of 250 and $500 \mu \mathrm{g} / \mathrm{ml}$ of fungal crude extract treated P. aeruginosa PAO1, respectively (Fig. 2D).

The results of GC-MS analysis revealed the presence of different metabolites in the fungal extract (Table S2). The major bioactive compounds present in P. sydowiana PPR extract are 2-aminoacetophenone, 2-furoic acid, 2phenylethanol, 2-(4-hydroxyphenyl) ethanol, N-phenethylacetamide, 4-HPA, and CLP.

\section{Molecular Modeling of RhIR and Molecular Docking}

The 3D structure of the RhlR receptor molecule was modeled from the protein sequence retrieved from UniPort database (ID: P54292.1) using the ROBETTA on-line web server for structure modeling. The overall stereo chemistry quality assessment of the modeled RhlR structure was performed in the RAMPAGE web server. The overall stereochemistry qualities of built 3D-model structures of RhlR were accessed based on the psi/phi Ramachandran plot and the result demonstrated $100 \%$ presence of the amino acid residues in the favored region.

Molecular docking conferred better information about the interaction of bioactive compounds with LasR and RhlR receptor proteins. Natural ligands such as 3-oxo- $\mathrm{C}_{12}-\mathrm{HSL}$ and $\mathrm{C}_{4}-\mathrm{HSL}$ were used as reference models in molecular docking analyses for ligand interacting domains of LasR and RhlR, respectively. The molecular docking studies of different bioactive compounds identified in the crude extract of $P$. sydowiana PPR revealed strong interaction with the receptor proteins. CLP exhibited the highest docking score of $-6.572 \mathrm{kcal} / \mathrm{mol}$ and it formed hydrogen bonds with residues Trp60, Thr115, and Ser129. These interactions and the score were comparatively equal to the natural ligand for LasR (Fig. S2). On the other hand, CLP had a docking score of $-6.383 \mathrm{kcal} / \mathrm{mol}$ with RhlR receptor and formed hydrogen bond with residue TRP-68, which is relatively higher than their respective natural ligands and positive controls (Fig. S3). Thus, we concluded that the compound CLP exhibited higher affinity than other compounds toward the QS receptor proteins (Table S3).

\section{Molecular Dynamics Simulation}

Molecular dynamics simulation studies were conducted to determine the conformational modification in LasR QS receptor protein in the presence of signaling molecules and bioactive compounds. The simulations were performed with four complexes, LasR- $\mathrm{C}_{12} \mathrm{HSL}$, LasR-BCL, LasR-CLP, and LasR-4-HPA. Similarly, the complexes of these ligands with RhlR were also subjected to the simulation process. The simulations were run for 50,000 ps with the time step of $2 \mathrm{fs}$. The root-mean-square deviation (RMSD) profile was generated to analyze the interaction of QS receptor proteins with the signaling molecules and bioactive compounds throughout the simulation process. The RMSD values of the complexes formed by QS receptors with their respective natural ligands and bioactive compounds were within the range of $2 \AA$, indicating accurate docking [45]. Overall, the
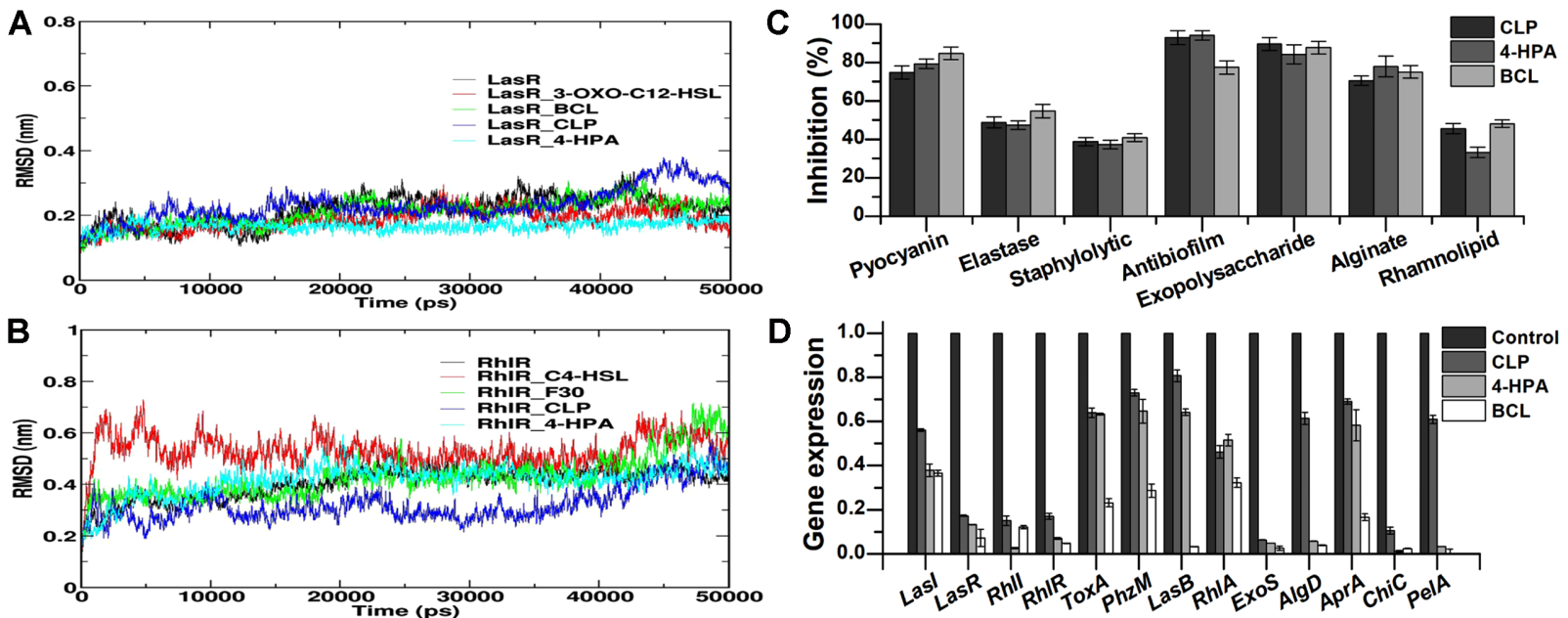

Fig. 4. Root-mean-square deviation (RMSD) analysis with time for cyclo(-Leu-Pro) (CLP), 4-Hydroxyphenylacetamide (4HPA), baicalein, and furanone C-30 along with (A) LasR and (B) RhlR. (C) Effect of bioactive compounds on the production of QSregulated virulence factors, biofilm, and its determinants in P. aeruginosa PAO1. (D) Relative expression levels of QS-related genes of P. aeruginosa PAO1 exposed with bioactive compounds. Normalized with the reference gene proC. The error bar symbolized the standard deviation of the three independent values. 
Table 2. MM/PBSA analysis: LasR and RhIR QS circuit with binding energy and their constituents (kJ/mol).

\begin{tabular}{|c|c|c|c|c|c|}
\hline Ligand ID & $\begin{array}{c}\text { Van der Waals } \\
\text { energy } \\
(\mathrm{kJ} / \mathrm{mol})\end{array}$ & $\begin{array}{l}\text { Binding } \\
\text { energy } \\
(\mathrm{kJ} / \mathrm{mol})\end{array}$ & $\begin{array}{c}\text { Electrostatic } \\
\text { energy } \\
(\mathrm{kJ} / \mathrm{mol})\end{array}$ & $\begin{array}{c}\text { Polar salvation } \\
\text { energy } \\
(\mathrm{kJ} / \mathrm{mol})\end{array}$ & $\begin{array}{c}\text { SASA } \\
\text { energy } \\
(\mathrm{kJ} / \mathrm{mol})\end{array}$ \\
\hline $\begin{array}{l}\text { LasR } \\
\mathrm{C}_{12}-\mathrm{HSL}\end{array}$ & -171.224 & -122.316 & -53.143 & 119.778 & -17.700 \\
\hline CLP & -119.284 & -52.930 & -34.116 & 112.670 & -12.179 \\
\hline 4-HPA & -157.057 & -100.375 & -122.486 & 193.563 & -14.433 \\
\hline BCL & -190.142 & -164.580 & -3.662 & 45.533 & -16.303 \\
\hline $\begin{array}{l}\text { RhlR } \\
\mathrm{C}_{4}-\mathrm{HSL}\end{array}$ & -105.598 & -51.274 & -45.407 & 111.066 & -11.321 \\
\hline Furanone C30 & -122.381 & -93.732 & -12.116 & 50.993 & -10.194 \\
\hline CLP & -78.249 & -35.813 & -22.521 & 73.401 & -8.499 \\
\hline 4-HPA & -109.390 & -95.881 & -63.915 & 88.025 & -10.654 \\
\hline
\end{tabular}

complexes were highly stable and RMSD values were maintained below $0.4 \mathrm{~nm}$. Individual analysis based on RMSD showed that the LasR-3-oxo- $\mathrm{C}_{12}$ HSL, LasR-BCL, LasR-CLP, and LasR-4HPA complexes were stable after $\sim 12,000$ ps, $\sim 14,000 \mathrm{ps}, \sim 20,000 \mathrm{ps}$, and $\sim 15,000 \mathrm{ps}$, respectively. The fluctuations observed after $\sim 35,000 \mathrm{ps}$ and $\sim 10,000$ ps as well as the stability were maintained till the end of the simulation (Fig. 4A). In the case of RhlR, RMSD values of all the complexes were maintained below $0.8 \mathrm{~nm}$. Individual analysis showed that the complex

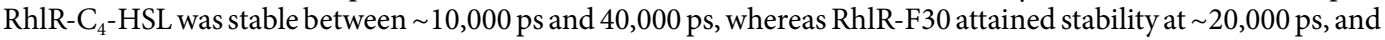
fluctuation was observed after 40,000 ps. RhlR-CLP maintained its stability between $\sim 10,000 \mathrm{ps}$ and 40,000 ps, whereas RhlR-4HPA complex was highly stable from $\sim 10,000$ ps and maintained its stability till the end of the simulation (Fig. 4B). The binding energy for LasR complex formation was $-122.316 \mathrm{~kJ} / \mathrm{mol}$ for $\mathrm{LasR}_{\mathrm{B}} \mathrm{C}_{12}-\mathrm{HSL}$, $-164.58 \mathrm{~kJ} / \mathrm{mol}$ for LasR-Baicalein, $-52.930 \mathrm{~kJ} / \mathrm{mol}$ for LasR-CLP and $-100.375 \mathrm{~kJ} / \mathrm{mol}$ for LasR-4HPA. In case of RhlR complexes, the binding energy values were $-51.274 \mathrm{~kJ} / \mathrm{mol}$ for RhlR- ${ }_{4} \mathrm{HSL},-93.732 \mathrm{~kJ} / \mathrm{mol}$ for RhlRFuranone C-30, $-35.813 \mathrm{~kJ} / \mathrm{mol}$ for RhlR-CLP and $-95.881 \mathrm{~kJ} / \mathrm{mol}$ for RhlR-4HPA (Table 2).

Effect of Bioactive Compounds of P. sydowiana PPR on the Growth of P. aeruginosa PAO1

The MIC of CLP, 4-HPA, and BCL (positive control) against $P$. aeruginosa PAO1 were determined. The MIC values of CPL and BCL against P. aeruginosa PAO1 were found to be $250 \mu \mathrm{g} / \mathrm{ml}$, whereas the MIC of 4-HPA from P. sydowiana PPR was $125 \mu \mathrm{g} / \mathrm{ml}$. Hence, the in vitro anti-QS and anti-biofilm activities of the selected bioactive compounds (CLP and BCL) were evaluated at the sub-MIC concentration of $125 \mu \mathrm{g} / \mathrm{ml}$. The in vitro anti-QS and anti-biofilm activities of 4-HPA were determined at the sub-MIC concentration of $62.5 \mu \mathrm{g} / \mathrm{ml}$. The sub-MIC concentrations of each bioactive compound and positive control were investigated for their effect on the growth of P. aeruginosa PAO1 using growth curve analysis. The experimental results revealed that the sub-MIC concentration had no adverse effect on the growth of P. aeruginosa PAO1 and growth curve patterns were similar to those of untreated control.

\section{Anti-QS Potential of Bioactive Compounds}

Pyocyanin is an important virulence factor secreted by P. aeruginosa, which is regulated by genes controlled by QS. The effect of fungal bioactive compounds on the synthesis of pyocyanin was evaluated. The results showed that the bioactive compounds from $P$. sydowiana PPR significantly affected the synthesis of pyocyanin by $P$. aeruginosa PAO1. At the sub-MIC concentration, CLP, 4-HPA, and BCL significantly inhibited the pyocyanin synthesis by P. aeruginosa $\mathrm{PAO} 1$ with inhibition of $74.72 \pm 3.42 \%, 79.22 \pm 2.41 \%$ and $84.73 \pm 3.28 \%$, respectively. CLP, 4-HPA, and BCL significantly inhibited elastase synthesis by $P$. aeruginos $a$ with inhibition of $48.78 \pm 2.82 \%, 47.31 \pm 2.27 \%$ and $54.76 \pm 3.49 \%$, respectively. The fungal bioactive compounds were evaluated for their ability to inhibit the staphylolytic activity of $P$. aeruginosa PAO1. At the sub-MIC concentration, CLP, 4-HPA, and BCL significantly inhibited the staphylolytic activity of $P$. aeruginosa PAO1 with inhibition of $38.71 \pm 2.11 \%, 37.25 \pm 2.29 \%$ and $40.83 \pm 1.97 \%$, respectively (Fig. $4 \mathrm{C}$ ). In addition to the QS-regulated virulence factors, the selected bioactive compounds significantly inhibited the biofilm formation too. At the sub-MIC concentration, CLP, 4-HPA, and BCL significantly inhibited the biofilm formation by $P$. aeruginosa PAO1 with inhibition of $92.91 \pm 3.56 \%, 94.10 \pm$ $2.51 \%$ and $77.37 \pm 3.51 \%$, respectively. On treatment with sub-MIC concentrations of $P$. sydowiana PPR bioactive compounds, the synthesis of QS-regulated biofilm determinants such as exopolysaccharides (EPS), alginates, and rhamnolipids was also significantly inhibited (Fig. 4C). Moreover, a significant reduction was observed in the swimming and swarming motility of $P$. aeruginosa PAO1 when treated with sub-MIC concentrations of CLP, 4$\mathrm{HPA}$, and BCL.

\section{Gene Expression Studies}

The RT-PCR results revealed the mRNA expression levels of different QS-regulated virulence genes of P. aeruginosa PAO1 on treatment with bioactive compounds CLP, 4-HPA, and BCL (positive controls). The expression levels of selected genes including LasI, LasR, RhlI, RhlR, ToxA, PhzM, LasB, RhlA, Exo, AlgD, AprA, $\mathrm{ChiC}$, and PelA were significantly reduced when treated with sub-MIC dosages in comparison to the untreated controls (Fig. 4D). 


\section{Discussion}

QS is a regulatory process that allows a bacterial population to collectively express various virulence factors associated with pathogenesis including biofilm formation [47-50]. Targeting the QS circuits of bacteria has been found to be a promising strategy to combat bacterial infections as an alternative to conventional antibiotics [51]. This therapeutic strategy potentially inhibits the production of pathogenic phenotypes of the bacteria without provoking any adverse effect on their growth. The marine ecosystem appeared to be a promising source of diverse biological active compounds with pharmaceutical applications [52]. The metabolites of different marine-derived bacteria, actinomycetes, and fungi were reported as potential inhibitors of QS and its regulatory factors [53]. In the present study we examined the potential of the marine-derived fungi as a source of antipathogenic molecules.

Zhang et al. [54] reported the anti-QS and antibiofilm activities of equisetin isolated from a marine fungus Fusarium sp. Z10 against P. aeruginosa PAO1. Screening of 14 fungal isolates as QSIs revealed that PPR exhibited significant effect. The fungal species Pestalotiopsis is known to have antimicrobial potential but not as QSI against P. aeruginosa. [55]. The present results revealed that the fungal extract significantly inhibited the las system, which was related to decrease in the production of elastase, alkaline protease, pyocyanin, chitinase, rhamnolipid, and swarming motility. This fungal isolate could significantly attenuate the QS-governed virulence traits in $P$. aeruginosa PAO1.

The present study also presented the effect of fungal extract on the production of rhamnolipids, EPS, and alginate, the major components of the biofilm $[30,56]$. Molecular docking study revealed that the metabolite (cyclo(-Leu-Pro) of PPR isolate adapts in the structure of receptor protein in a likely fashion to the natural ligands and positive controls (Figs. S2 and S3). RMSD profile revealed that throughout the simulation, complexes of both the QS receptors with bioactive compounds were equally stable when compared with the LasR signaling molecule complex. Hnamte et al. [46] suggested that docking analysis may be useful to demonstrate the anti-QS efficiency of phytochemicals. Molecular dynamics simulation studies demonstrated that mosloflavone can act as an anti-QS agent against $P$. aeruginosa $\mathrm{PAO}$.

Among the different metabolites of $P$. sydowiana PPR, two bioactive compounds, CLP and 4-HPA, were determined as significant compounds and shown to inhibit the synthesis of QS-regulated virulence determinants and biofilm formation in P. aeruginosa PAO1. To the best of our knowledge, no attempt has been made to explore the anti-QS and antibiofilm activities of these bioactive compounds from P. sydowiana PPR against $P$. aeruginosa PAO1. The experimental results of this study showed the potential of these bioactive compounds to inhibit the synthesis of QS-regulated pathogenic factors and biofilm formation. These compounds can be used as anti-QS agents to exert non-lethal effect on the growth of $P$. aeruginosa PAO1, to abate the possibility of drug resistance.

As mentioned previously, QS plays a significant role in the pathogenicity of $P$. aeruginosa $\mathrm{PAO} 1$ by regulating various virulence genes and subsequently mediating the synthesis of virulence factors. The major QS-related genes as well as virulence genes, which are regulated by the QS system in P. aeruginosa PAO1, were analyzed using RT-PCR to evaluate the expression level when the bacterial strain was treated with or without the bioactive compounds. The experimental results of gene expression analysis revealed that the bioactive compounds significantly downregulated the expression of all the genes analyzed. In particular, the expression levels of lasI, lasR, $r h l I$, and $r h l R$ were significantly reduced (Fig. 4D). Since las $I / R$ and $r h l I / R$ are the major regulatory genes of the P. aeruginosa PAO1 QS system, targeted downregulation of these genes would inhibit the QS circuit, which can subsequently impair the pathogenicity associated with the QS system.

In conclusion, the effect of metabolites from P. sydowiana PPR on QS system and its regulatory pathogenic phenotypes in $P$. aeruginosa PAO1 were revealed. The bioactive compounds produced by the fungus exhibited promising inhibition of virulence traits, motility, and biofilm formation. The molecular docking and molecular dynamics simulation studies revealed a significant interaction of fungal metabolites with the QS receptor proteins of test bacterium. The present study demonstrated for the first time that CLP and 4-HPA produced by $P$. sydowiana PPR suppress the synthesis of several QS-associated virulence factors in $P$. aeruginosa PAO1 without affecting the bacterial growth. These results concluded that the metabolites of $P$. sydowiana PPR could potentially inhibit the QS system and limit the degree of pathogenicity in P. aeruginosa PAO1.

\section{Acknowledgments}

We sincerely acknowledge Dr. G. Muralitharan, Department of Microbiology, Bharathidasan University, Tiruchirappalli for providing the Confocal Laser Scanning Microscope facility. This research work was financially supported by start-up research grant from Department of Science and Technology-The Science \& Engineering Research Board (SB/YS/LS-32/2014). V.V. Sarma would like to offer his sincere gratitude to the grant of the Ministry of Earth Sciences, Government of India, under Sanction order: MOES/36/OO1S/Extra/40/2014/PC-IV dt.14.1.2015). This research was supported by Brain Pool grant (NRF-2019H1D3A2A01060226) by the National Research Foundation of Korea for work at Konkuk University (VCK). This research was also supported by the Basic Science Research Program through the NRF funded by the Ministry of Science, ICT \& Future Planning [2019R1F1A1063131 (IWK) and 2019R1C1C1009766 (SKSP)].

\section{Conflict of Interest}

The authors have no financial conflicts of interest to declare. 


\section{References}

1. Kalia VC. 2013. Quorum sensing inhibitors: An overview. Biotechnol. Adv. 31: 224-245

2. Kalia VC, Patel SKS, Kang YC, Lee J-K. 2019. Quorum sensing inhibitors as antipathogens: biotechnological applications. Biotechnol. Adv. 37: 68-90.

3. Kalia VC. 2014. In search of versatile organisms for quorum-sensing inhibitors: acyl homoserine lactones (AHL)-acylase and AHLlactonase. FEMS Microbiol. Lett. 359: 143-143.

4. Kalia VC. 2014. Microbes, antimicrobials and resistance: The battle goes on. Indian J. Microbiol. 54: 1-2.

5. Kalia VC, Purohit HJ. 2011. Quenching the quorum sensing system: potential antibacterial drug targets. Crit. Rev. Microbiol. 37: 121140.

6. Kumar P, Patel SKS, Lee J-K, Kalia VC. 2013. Extending the limits of Bacillus for novel biotechnological applications. Biotechnol. Adv. 31: $1543-1561$

7. Kalia VC, Raju SC, Purohit HJ. 2011. Genomic analysis reveals versatile organisms for quorum quenching enzymes: AcylHomoserine lactone-Acylase and -Lactonase. Open Microbiol. J. 3: 1-11.

8. Huma N, Shankar P, Kushwah J, Bhushan A, Joshi J, Mukherjee T, et al. 2011. Diversity and polymorphism in AHL-lactonase gene (aiiA) of Bacillus. J. Microbiol. Biotechnol. 21: 1001-1011.

9. Kostylev M, Kim DY, Smalley NE, Salukhe I, Greenberg EP, Dandekar AA. 2019. Evolution of the Pseudomonas aeruginosa quorumsensing hierarchy. Proc. Natl. Acad. Sci. USA 116: 7027-7032.

10. Lee K, Yoon SS. 2017. Pseudomonas aeruginosa biofilm, a programmed bacterial life for fitness. J. Microbiol. Biotechnol. 27: 10531064.

11. Yong Y-C, Zhong J-J. 2013. Impacts of quorum sensing on microbial metabolism and human health, pp. 25-61. In Zhong J-J (ed.), Future Trends in Biotechnology, Advances in Biochemical Engineering/Biotechnology, vol. 131. Springer, Berlin, Heidelberg.

12. Mulcahy LR, Isabella VM, Lewis K. 2014. Pseudomonas aeruginosa biofilms in disease. Microb. Ecol. 68: 1-12.

13. Ding F, Oinuma K-I, Smalley NE, Schaefer AL, Hamwy O, Peter Greenberg E, et al. 2018. The Pseudomonas aeruginosa orphan quorum sensing signal receptor QscR regulates global quorum sensing gene expression by activating a single linked operon. $m$ Bio. 9 : e01274-18.

14. Sun S, Dai X, Sun J, Bu X, Weng C, Li H, Zhu H. 2016. A diketopiperazine factor from Rheinheimera aquimaris QSI02 exhibits antiquorum sensing activity. Sci. Rep. 6: 39637.

15. Kim A-L, Park S-Y, Lee CH, Lee C-H, Lee J-K. 2014. Quorum quenching bacteria isolated from the sludge of a wastewater treatment plant and their application for controlling biofilm formation. J. Microbiol. Biotechnol. 24: 1574-1582.

16. Lade H, Paul D, Kweon JH. 2015. Combined effects of curcumin and (-)-epigallocatechin gallate on inhibition of n-acylhomoserine lactone-mediated biofilm formation in wastewater bacteria from membrane bioreactor. J. Microbiol. Biotechnol. 25: 1908-1919.

17. Yap PSX, Krishnan T, Chan K-G, Lim SHE. 2015. Antibacterial mode of action of Cinnamomum verum bark essential oil, alone and in combination with piperacillin, against a multi-drug-resistant Escherichia coli strain. J. Microbiol. Biotechnol. 25: 1299-1306.

18. Jo SJ, Kwon H, Jeong S-Y, Lee SH, Oh H-S, Yi T, et al . TG. 2016. Effects of quorum quenching on the microbial community of biofilm in an anoxic/oxic MBR for wastewater treatment. J. Microbiol. Biotechnol. 26: 1593-1604.

19. Zhang L, Guo Z, Gao H, Peng X, Li Y, Sun S, Lee J-K, et al. 2016. Interaction of Pseudostellaria heterophylla with quorum sensing and quorum quenching bacteria mediated by root exudates in a consecutive monoculture system. J. Microbiol. Biotechnol. 26: 2159-2170.

20. Choi H-A, Cheong D-E, Lim H-D, Kim W-H, Ham M-H, Oh M-H, et al. 2017. Antimicrobial and anti-biofilm activities of the methanol extracts of medicinal plants against dental pathogens Streptococcus mutans and Candida albicans. J. Microbiol. Biotechnol. 27: $1242-1248$

21. Kang S-Y, Kim B-M, Heo KT, Jang J-H, Kim W-G, Hong Y-S. 2017. Production of bacterial quorum sensing antagonists, caffeoyland feruloyl-HSL, by an artificial biosynthetic pathway. J. Microbiol. Biotechnol. 27: 2104-2111.

22. Lee SH, Lee S, Lee K, Nahm CH, Jo SJ, Lee J, et al. 2017. Enhancing the physical properties and lifespan of bacterial quorum quenching media through combination of ionic cross-linking and dehydration. J. Microbiol. Biotechnol. 27: 552-560.

23. Wang J, Nong X-H, Zhang X-Y, Xu X-Y, Amin M, Qi S-H. 2017. Screening of anti-biofilm compounds from marine-derived fungi and the effects of secalonic acid D on Staphylococcus aureus biofilm. J. Microbiol. Biotechnol. 27: 1078-1089.

24. Ham Y, Kim T-J. 2018. Nitrogen sources inhibit biofilm formation of Xanthomonas oryzae pv. oryzae. J. Microbiol. Biotechnol. 28: 2071-2078.

25. Ahmad MS, El-Gendy AO, Ahmed RR, Hassan HM, El-Kabbany HM, Merdash AG. 2017. Exploring the antimicrobial and antitumor potentials of Streptomyces sp. AGM12-1 isolated from Egyptian soil. Front. Microbiol. 8: 438.

26. Vasavi HS, Arun AB, Rekha PD. 2016. Anti-quorum sensing activity of flavonoid-rich fraction from Centella asiatica L. against Pseudomonas aeruginosa PAO1. J. Microbiol. Immunol. Infect. 49: 8-15.

27. Miao L, Xu J, Yao Z, Jiang Y, Zhou H, Jiang W, Dong K. 2017. The anti-quorum sensing activity and bioactive substance of a marine derived Streptomyces. Biotechnol. Biotechnol. Equip. 31: 1007-1015.

28. Shukla V, Bhathena Z. 2016. Broad spectrum anti-quorum sensing activity of tannin-rich crude extracts of Indian medicinal plants. Scientifica (Cairo). 2016: 1-8.

29. Kalia M, Yadav VK, Singh PK, Sharma D, Pandey H, Narvi SS, Agarwal V. 2015. Effect of cinnamon oil on quorum sensingcontrolled virulence factors and biofilm formation in Pseudomonas aeruginosa. PLoS One 10: e0135495.

30. Ma Z-P, Song Y, Cai Z-H, Lin Z-J, Lin G-H, Wang Y, et al. 2018. Anti-quorum sensing activities of selected coral symbiotic bacterial extracts from the South China sea. Front. Cell. Infect. Microbiol. 8: 144.

31. Hossain MA, Lee S-J, Park N-H, Mechesso AF, Birhanu BT, Kang J, et al. 2017. Impact of phenolic compounds in the acyl homoserine lactone-mediated quorum sensing regulatory pathways. Sci. Rep. 7: 10618.

32. Musthafa KS, Saroja V, Pandian SK, Ravi AV. 2011. Antipathogenic potential of marine Bacillus sp. SS4 on N-acyl-homoserinelactone-mediated virulence factors production in Pseudomonas aeruginosa (PAO1). J. Biosci. 36: 55-67.

33. Husain FM, Ahmad I, Al-thubiani AS, Abulreesh HH, AlHazza IM, Aqil F. 2017. Leaf extracts of Mangifera indica L. inhibit quorum sensing - regulated production of virulence factors and biofilm in test bacteria. Front. Microbiol. 8: 1-12.

34. Adonizio A, Kong K-F, Mathee K. 2008. Inhibition of quorum sensing-controlled virulence factor production in Pseudomonas aeruginosa by South Florida plant extracts. Antimicrob. Agents Chemother. 52: 198-203.

35. Li T, Mei Y, He B, Sun X, Li J. 2019. Reducing quorum sensing-mediated virulence factor expression and biofilm formation in hafnia alvei by using the potential quorum sensing inhibitor L-carvone. Front. Microbiol. 9: 3324.

36. Yin H, Deng Y, Wang H, Liu W, Zhuang X, Chu W. 2015. Tea polyphenols as an antivirulence compound disrupt quorum-sensing regulated pathogenicity of Pseudomonas aeruginosa. Sci. Rep. 5: 16158.

37. Lee J-H, Kim Y-G, Yong Ryu S, Lee J. 2016. Calcium-chelating alizarin and other anthraquinones inhibit biofilm formation and the hemolytic activity of Staphylococcus aureus. Sci. Rep. 6: 19267.

38. Luo J, Dong B, Wang K, Cai S, Liu T, Cheng X, et al. 2017. Baicalin inhibits biofilm formation, attenuates the quorum sensingcontrolled virulence and enhances Pseudomonas aeruginosa clearance in a mouse peritoneal implant infection model. PLoS One 12: e0176883. 
39. Gopu V, Meena CK, Shetty PH. 2015. Quercetin influences quorum sensing in food borne bacteria: in-vitro and in-silico evidence. PLoS One 10: e0134684.

40. Singh G, Kumar P. 2013. Extraction, gas chromatography-mass spectrometry analysis and screening of fruits of Terminalia chebula Retz. for its antimicrobial potential. Pharmacognosy Res. 5: 162.

41. Lovell SC, Davis IW, Arendall WB, de Bakker PIW, Word JM, Prisant MG, et al. 2003. Structure validation by Ca geometry: $\phi, \psi$ and C $\beta$ deviation. Proteins 50: 437-450.

42. Husain FM, Ahmad I, Baig MH, Khan MS, Khan MS, Hassan I, et al. 2016. Broad-spectrum inhibition of AHL-regulated virulence factors and biofilms by sub-inhibitory concentrations of ceftazidime. RSC Adv. 6: 27952-27962.

43. Friesner RA, Murphy RB, Repasky MP, Frye LL, Greenwood JR, Halgren TA, et al. 2006. Extra precision glide: docking and scoring incorporating a model of hydrophobic enclosure for protein-ligand complexes. J. Med. Chem. 49: 6177-6196.

44. Abraham MJ, Murtola T, Schulz R, Páll S, Smith JC, Hess B, et al. 2015. GROMACS: High performance molecular simulations through multi-level parallelism from laptops to supercomputers. SoftwareX 2: 19-25.

45. Rajkumari J, Borkotoky S, Reddy D, Mohanty SK, Kumavath R, Murali A, et al. 2019. Anti-quorum sensing and anti-biofilm activity of 5-hydroxymethylfurfural against Pseudomonas aeruginosa PAO1: Insights from in vitro, in vivo and in silico studies. Microbiol. Res. 226: 19-26.

46. Hnamte S, Parasuraman P, Ranganathan S, Ampasala DR, Reddy D, Kumavath RN, et al. 2019. Mosloflavone attenuates the quorum sensing controlled virulence phenotypes and biofilm formation in Pseudomonas aeruginosa PAO1: In vitro, in vivo and in silico approach. Microb. Pathog. 131: 128-134.

47. Rutherford ST, Bassler BL. 2012. Bacterial quorum sensing: its role in virulence and possibilities for its control. Cold Spring Harb. Perspect. Med. 2: a012427.

48. Hussain MS, Oh D-H. 2018. Impact of the isolation source on the biofilm formation characteristics of Bacillus cereus. J. Microbiol. Biotechnol. 28: 77-86.

49. Jin W, Lin H, Gao H, Guo Z, Li J, Xu Q, et al. 2019. N-acyl-homoserine lactone quorum sensing switch from acidogenesis to solventogenesis during the fermentation process in Serratia marcescens MG1. J. Microbiol. Biotechnol. 29: 596-606.

50. Lim ES, Kim J-S. 2017. Role of eptC in biofilm formation by Campylobacter jejuni NCTC11168 on polystyrene and glass surfaces. J. Microbiol. Biotechnol. 27: 1609-1616.

51. Hançer Aydemir D, Çifci G, Aviyente V, Boşgelmez-Tinaz G. 2018. Quorum-sensing inhibitor potential of trans -anethole aganist Pseudomonas aeruginosa. J. Appl. Microbiol. 125: 731-739.

52. Lindequist U. 2016. Marine-derived pharmaceuticals - challenges and opportunities. Biomol. Ther. (Seoul). 24: 561-571.

53. Chen J, Wang B, Lu Y, Guo Y, Sun J, Wei B, Zhang H, Wang H. 2019. Quorum sensing inhibitors from marine microorganisms and their synthetic derivatives. Mar. Drugs. 17: 80 .

54. Zhang M, Wang M, Zhu X, Yu W, Gong Q. 2018. Equisetin as potential quorum sensing inhibitor of Pseudomonas aeruginosa. Biotechnol. Lett. 40: 865-870.

55. Sharma D, Pramanik A, Agrawal PK. 2016. Evaluation of bioactive secondary metabolites from endophytic fungus Pestalotiopsis neglecta BAB-5510 isolated from leaves of Cupressus torulosa D.Don. 3 Biotech 6: 210 .

56. Koh CL, Sam CK, Yin WF, Tan LY, Krishnan T, Chong YM, et al. 2013. Plant-derived natural products as sources of anti-quorum sensing compounds. Sensors (Basel). 13: 6217-6228. 